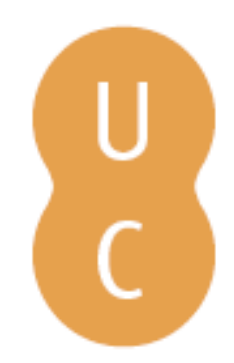

\title{
Rompalina
}

\section{Egas Moniz: um cientista em viagens: internacionalização como estratégia}

\author{
Autor(es): $\quad$ Correia, Manuel
}

Publicado por: Imprensa da Universidade de Coimbra

URL

persistente: URI:http://hdl.handle.net/10316.2/32394

DOI: $\quad$ DOI:http://dx.doi.org/10.14195/978-989-26-0469-5_13

Accessed : $\quad$ 26-Apr-2023 11:55:35

A navegação consulta e descarregamento dos títulos inseridos nas Bibliotecas Digitais UC Digitalis, UC Pombalina e UC Impactum, pressupõem a aceitação plena e sem reservas dos Termos e Condições de Uso destas Bibliotecas Digitais, disponíveis em https://digitalis.uc.pt/pt-pt/termos.

Conforme exposto nos referidos Termos e Condições de Uso, o descarregamento de títulos de acesso restrito requer uma licença válida de autorização devendo o utilizador aceder ao(s) documento(s) a partir de um endereço de IP da instituição detentora da supramencionada licença.

Ao utilizador é apenas permitido o descarregamento para uso pessoal, pelo que o emprego do(s) título(s) descarregado(s) para outro fim, designadamente comercial, carece de autorização do respetivo autor ou editor da obra.

Na medida em que todas as obras da UC Digitalis se encontram protegidas pelo Código do Direito de Autor e Direitos Conexos e demais legislação aplicável, toda a cópia, parcial ou total, deste documento, nos casos em que é legalmente admitida, deverá conter ou fazer-se acompanhar por este aviso.

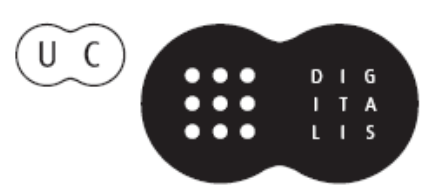


Ana Leunar Pereira João Rui Pita

[ Coordenaçä̃ ]
Rotas da Natureza

Cientistas

Viagens

Expedifgũes

Instituip̧ües

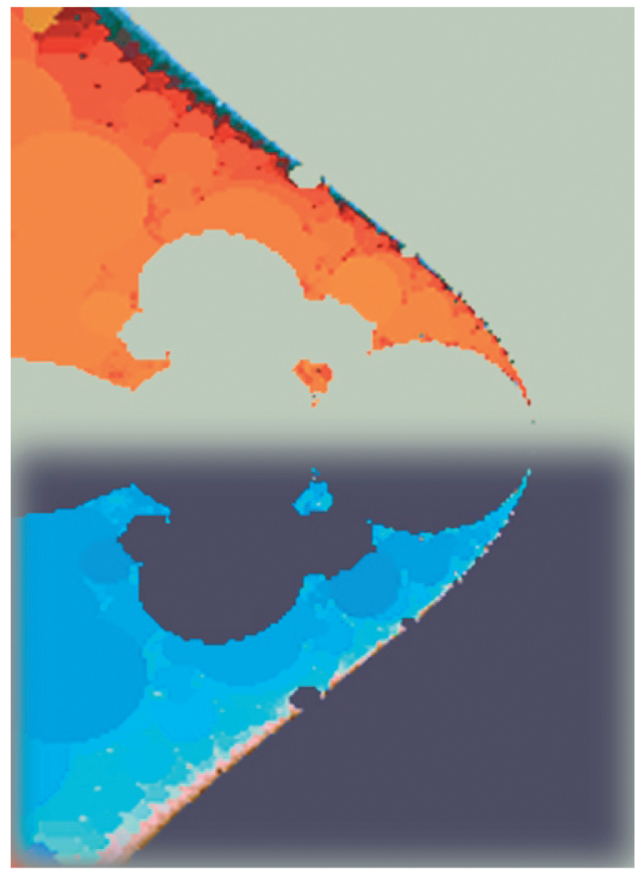




\section{Coordenaçáo Científica da Colecção Ciências e Culturas}

João Rui Pita e Ana Leonor Pereira

Os originais enviados são sujeitos a apreciação científica por referees

\section{Coordenação Editorial}

Maria João Padez Ferreira de Castro

\section{Edição}

Imprensa da Universidade de Coimbra

Email:impresauc@ci.uc.pt

URL: http://www.imp.uc.pt • Normas de publicação de colecçôes

\section{Design}

António Barros

Pré-Impressáo

António Resende

Imprensa da Universidade de Coimbra

\section{Capa}

António Barros, com imagem de E. M. de Melo e Castro, 2003 [Fractal original gerado no Fractint com tratamento no Photoshop 7.0]; Cortesia: António Barros

Impressão e Acabamento

SerSilito • Maia

\section{ISBN}

978-989-8074-12-6

\section{Depósito Legal}

Obra publicada com a colaboraçáo de:
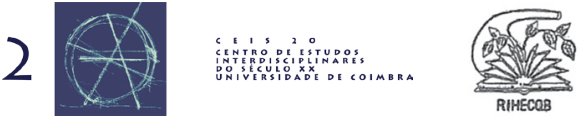

Obra publicada com o apoio de:

FCT Fundação para a Ciência e a Tecnologia

MINISTÉRIO DA CIÊNCIA, TECNOLOGIA E ENSINO SUPERTOR Portug

Programa Operacional Ciência, Tecnologia, Inovação do Quadro Comunitário de Apoio III
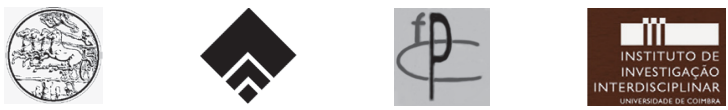

\section{Baxter}

(c) 2006, Imprensa da Universidade de Coimbra 
João Rui Pita

Ana Leonar Pereira

(Courdenação)

Rotas da Natureza

Cientistas

Viagens

Expediçũes

Instituiç̃̃es

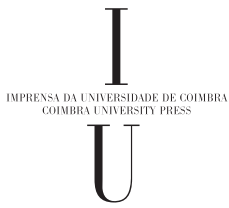

- colmbra 2006 
(Página deixada propositadamente em branco) 


\section{Manuel Correia}

Bolseiro de doutoramento da FCT. Colaborador do Centro de Estudos Interdisciplinares do Século XX da Universidade de Coimbra, CEIS20 (Grupo de História e Sociologia da Ciência), Portugal

\section{EGAS MONIZ: UM CIENTISTA EM VIAGENS. A INTERnaCionalizaÇÃo COMO ESTRATÉgia}

O relacionamento internacional com centros de produção de conhecimento científico e técnico foi para Egas Moniz, mais do que uma necessidade premente, um critério explícito de aferição de cultura científica acerca do qual teorizou esparsamente. Necessidade incontornável, tal como era vivida pelos cientistas mais esclarecidos do seu tempo, de reconhecer as rotas e as redes, os pontos de passagem mais importantes, e os mestres neurologistas que se tinham constituído em referência. Paralelamente, a publicação de resultados e observações, subordinava-se também a essa mundividência, levando a que as respectivas traduções fossem asseguradas, mesmo nos momentos mais infelizes e dramáticos do que viria a ser o primeiro cientista português galardoado com o prémio Nobel da Medicina ou Fisiologia em 1949.

A participação em reuniōes internacionais - encontros, conferências e congressos - e também a organização de alguns desses fora, decorre da mesma postura que aproxima lugares afastados, (centros internacionais de produção de autoridade e credenciação científica), compondo o quadro rigoroso das cidades e sumidades que então valia a pena visitar, frequentar e manter em contacto.

No texto seguinte tentamos reconstituir o mapa e as ideias-chave que levaram Egas Moniz a estabelecer, gerir e alargar uma rede de contactos deliberadamente orientada para a internacionalização dos seus trabalhos e da sua figura, permitindo, ao mesmo tempo, a rápida percepção das inovações que se iam operando noutros lugares.

De acordo com teorias implícitas em que as nossas culturas são férteis, o homem viajado é um homem fascinante, detentor de uma visão mais alargada das coisas do mundo. $\mathrm{O}$ imobilismo relativo daqueles que vivem praticamente toda a vida sem se ausentarem do mesmo sítio ou da mesma região, é desprezado em favor da iniciativa viajante, tanto mais valorizada quanto mais sonantes forem os lugares visitados e os trajectos empreendidos. A ideia de «descobrimentos» é, a esse respeito, incontornável. A literatura de viagens está recenseada na história da Literatura Portuguesa desde, pelo menos, o século XVI, com Francisco Álvares e a sua obra Verdadeira Informação das Terras do Prestes João, mas quer o surgimento das concepções planetárias da história, quer as inumeráveis expedições político-científicas que coloriram as rotas cujos pontos de partida e retorno se situavam nas grandes capitais da Europa, são igualmente 
sugestivas. O alargamento dos territórios do saber e do poder seguiu paralelamente, em múltiplas ocasiōes.

A afirmação identitária de Egas Moniz, aspirando a progressões sucessivas dos seus estatutos político e académico, (primeiro) e científico (depois), foi sempre atravessada pela necessidade da deslocação (interna e externa), da viagem e da visita. Tudo isso sobre um roteiro preciso e esquematizado de acordo com uma estratégia bem definida.

A precedência de objectivos estratégicos emerge dos escritos de Egas Moniz com tal nitidez que, para além do objectivo científico e de uns curtos apontamentos acerca das circunstâncias da viagem, tudo o resto parece deslizar para as excursões de carácter histórico-filosófico, em que o inventor da Angiografia Cerebral discorre acerca da história da cultura, recorrendo a formulações anteriores, sem lhes acrescentar qualquer nota pessoal de observação.

De certo modo, o mundo que Egas Moniz quis visitar, conhecer melhor, e incluir no seu roteiro específico, era um mundo já duplamente «descoberto», em virtude dos estágios de especialização em neurologia, em França, logo a seguir à sua formatura em Coimbra, e das suas actividades políticas anteriores, designadamente resultantes da sua passagem pela pasta ministerial dos Negócios Estrangeiros, durante o Sidonismo. Era também um mundo cujos pontos de aproximação estavam intimamente associados às experiências mais avançadas no campo da neurologia.

Ao associar-se, de perto, aos cientistas de nomeada no seu campo, EM procedia à complementar construção da autoridade e da notoriedade, reforçando a sua posição em Portugal e, simultaneamente, constituindo-se em interlocutor avisado no plano internacional.

Enumerando aqueles que considerou seus mestres, EM enfatiza frequentemente a dimensão «viajante». De Augusto Rocha, por exemplo, diz ser um «dos poucos mestres viajados» ${ }^{1}$. A implícita censura ao imobilismo dos «outros», acantonados na rotina estagnante, torna-se por vezes mais expressa, sendo uma constante no seu critério de avaliação da competência científica.

Num elogio misto do experimentalismo, reflexão própria e contacto internacional, EM escreve a certo passo:

«As Universidades não podem nem devem ser constituídas por aqueles que apenas se contentam com a ciência feita» ${ }^{2}$.

Sugere, assim, que a avaliação dos professores deveria ser ponderada desse modo, no qual a inquirição acerca dos contactos científicos internacionais ocupava um lugar de relevo, mostrando a sua preferência pelos que

«(...) continuavam a receber estímulos dos centros científicos estrangeiros, convivendo com mestres competentes e dinâmicos (...) ${ }^{3}$

\footnotetext{
${ }^{1}$ Moniz, 1949, 10) doravante CIC.

${ }^{2}$ CIC, 20.

${ }^{3}$ CIC, p. 18.
} 
A par das numerosas referências a Ramón y Cajal de cuja obra reteve não apenas a concepção neuronal mas, tudo leva a crer, algo também do método contrastante ${ }^{4}$ por ele posto em prática, Egas Moniz aponta a França como lugar de eleição. Para além das razões já apontadas, relacionadas com os estágios de especialização e com a actividade política, virá a visitar a pátria de Voltaire também, depois, por questôes ingentes relacionadas com a afirmação, defesa e consolidação das suas posições no campo da neurologia e da Psico-cirurgia. No livro "Confidências de um Investigador Científico", que o próprio EM considera a sua melhor obra, confirma-o:

«O que sou em ciência devo-o à França, aos seus Mestres, ao seu ensino e especialmente ao estímulo que imprimem aos frequentadores das suas clínicas para estudarem e progredirem.» 5

É esse o primeiro eixo estruturante das rotas preferenciais que EM desenhou para se conferir a si próprio e ao seu trabalho uma dimensão internacional, uma visibilidade tão nítida como a que pretendia para a sua Angiografia Cerebral. Com a divulgação dos primeiros resultados da Arteriografia, o mapa virá a diversificar-se, e a sua rede de contactos a alargar-se. Porém é em França que EM faz os seus primeiros e decisivos investimentos.

Assim, a França surge na estratégia de EM como a primeira placa giratória para as comunidades médicas e científicas.

Tão cedo estima estar na posse de elementos de prova, suficientemente sólidos para iniciar o processo de aceitação da sua Arteriografia Cerebral, decide, de imediato, deslocar-se a Paris com o fito de obter uma primeira avaliação positiva por parte dos seus mestres.

Paralelamente, apresenta comunicaçôes sobre o mesmo assunto à Sociedade de Neurologia - de que Babinski, um dos seus mestres, foi co-fundador - e à Academia de Medicina de Paris.

«Só depois da aceitação pelos grandes nomes da neurologia francesa é que, já seguro da situação, comunicou os seus achados em Portugal, em especial à Academia de Ciências e à Faculdade de Medicina ${ }^{6} . »$

O mapa geográfico e a correspondente rede de contactos, alargam-se, nos anos seguintes, à Alemanha, Brasil, Inglaterra, Itália, Japão e Suécia. À medida que a Angiografia Cerebral é replicada e adoptada, os novos contactos sucedem-se, granjeando-lhe prestígio e influência crescentes.

A viagem que decide fazer a Paris imediatamente após ter conseguido, com Almeida Lima, a primeira Arteriografia Cerebral, decorre sob forte emoção, mas tal não significa que não tenha sido objecto de meticulosa preparação. Tudo leva a crer que essa

\footnotetext{
${ }^{4} \mathrm{O}$ método é da autoria de Camillo Golgi, que ganhou o Prémio Nobel de Medicina ou Fisiologia no mesmo ano de 1906, ex-aequo com Rámon y Cajal.

5 CIC, 69.

${ }^{6}$ Fernandes, 1983.
} 
viagem fez parte de uma estratégia longamente amadurecida. Se é certo que Moniz afirma recordar-se de inúmeros pormenores, que traduz sob a forma de apontamentos paisagísticos, entrecortados por manifestações de enervamento e ansiedade

«[Ainda em viagem, já] vagueava por Paris na inquietação dos momentos sempre angustiosos que marcam as grandes exibições.» ${ }^{7}$

também é verdade que a agenda de encontros, reuniōes e apresentação de comunicações foi cuidadosamente estabelecida. Além dos encontros prévios com Babinski, por um lado, e Souques, por outro, EM receberá, durante a sua estadia em Paris, as «chapas» que pedira para Almeida Lima lhe enviar de Lisboa, de modo a completar as apresentações programadas. Mesmo naquilo que poderia parecer menos importante, EM empenha-se com denodo: lembra aos convivas da casa de Babinski que elogiavam desmedidamente um Cognac servido no final da refeição, que o vinho do Porto possui um paladar e uma textura excepcionais, presenteando-os com uma prova das garrafas que trouxera de Portugal, para o efeito.

Esta atenção aos mínimos pormenores e a capacidade de planificação serviram a estratégia delineada por EM que visava

1) o estabelecimento da autoria da Arteriografia Cerebral (capital para mais tarde fazer prova de precedência, como foi o caso)

2) a exposição das virtualidades da sua criação perante os seus pares e

3) colocar-se num patamar superior de autoridade científica ${ }^{8}$.

Apesar de nem tudo lhe ter corrido bem no Hospital Necker, quando se tratou da replicar a experiência descrita nas suas comunicações, EM regista em tom proclamatório:

«Já podiam agredir-me os médicos patrícios, sempre prontos a amesquinhar o esforço dos conterrâneos e a deitar ao desprezo as conquistas científicas alcançadas no país. Os Mestres parisienses em que confiava tinham julgado em última instância, e a minha obra avultava aos meus próprios olhos como sempre a vira, mas agora com uma solidez que o meu exclusivo critério não era suficiente para lhe dar» ${ }^{9}$

Estava claro que, para além do valor que ele próprio atribuía à sua criação, ela só se consubstanciaria numa tecnologia de diagnóstico partilhada com a condição de

\footnotetext{
7 CIC, 66.

${ }^{8}$ Maria Helena Roque, num curto ensaio versando também a problemática das Viagens, enfatiza diferentes dimensōes: «As viagens de Egas Moniz organizaram-se em torno de quatro vectores fundamentais, a saber:1. Formação: absorção de conhecimentos e técnicas. 2. Amadurecimento: transferência e aplicação dos modelos apropriados. 3. Criação: ampliação e descoberta de novos métodos. 4. Difusão: disseminação das criações originais.» (Roque, 2000).

${ }^{9} \mathrm{CIC}, 91$.
} 
vencer as resistências ${ }^{10}$ à mudança implicada por qualquer inovação e na concomitante construção da notoriedade com o que ela implica de autoridade, reconhecimento e afirmação.

Praticamente em seguida, é convidado a participar na Semana Médica de Bruxelas, já na qualidade de Presidente da Academia de Ciências de Lisboa e, pouco depois, Aloysio de Castro formula-lhe o convite oficial de visitar o Brasil, onde participará numa série de reuniões e proferirá conferências, quer no Rio de Janeiro, quer em São Paulo.

Nas suas memórias, a descrição destas viagens é mais sucinta. O nervosismo e a ansiedade deixam de ser mencionados. Todavia, a boa impressão que deixou entre os colegas brasileiros valer-lhe-á mais tarde, em retorno, consecutivos apoios e nomeaçóes para o Prémio Nobel.

De um modo ou de outro, EM estabelece laços sólidos com lugares e pessoas. Dotado de um sentido agudo da diplomacia, potenciado pela sua experiência política anterior, dispõe os seus trunfos metodicamente. ${ }^{11}$

João Lobo Antunes frisa a este propósito que, para além da publicação tempestiva de artigos em revistas famosas, de circulação internacional, como a Lancet e o New England Journal of Medicine

«Egas Moniz tinha entre os seus colaboradores verdadeiros embaixadores que vão praticar a técnica angiográfica em serviços estrangeiros, como o de Cairns, em Londres, ou o de Olivecrona, em Estocolmo.» ${ }^{12}$

Ao arrepio da vitimização simplificadora que exagera os feitos de EM, com intuitos panegíricos, contributos recentes têm permitido uma abordagem mais profunda e descomplexada do significado e alcance do homem, da obra e dos contextos correlativos. É de elementar justiça referir, para além dos textos já citados, os trabalhos de Ana Leonor Pereira e João Rui Pita, de António Fernando Cascais e Tiago Moreira, entre outros. Este último, de acordo com um dos pressupostos capitais da corrente teórica em que se inscreve, qualifica o acesso que EM tinha aos meios internacionais como uma espécie de vantagem comparativa:

«Director do Serviço de Neurologia do Hospital de Santa Marta e professor de Neurologia Clínica na Faculdade de Medicina de Lisboa (...). Tinha poder e recursos. Tinha relaçôes com um dos centros mundiais da neurologia, França» ${ }^{13}$

\footnotetext{
${ }^{10}$ Tiago Moreira chama a atenção, a justo título, para a circunstâncias em que decorreu a primeira tentativa de replicação da arteriografia cerebral no Hospital Necker, considerando-as "primeiras resistências», o que no quadro da ANT - Actor Network Theory, constitui uma fase incontornável na realização de qualquer inovação tecnológica.

11 «[EM] conseguiu quase sempre concretizar os seus projectos, mas foi esta vontade audaz, a capacidade argumentativa, o sentido da oportunidade e a perícia diplomática que lhe permitiram desenvolver os trabalhos de investigação e divulgá-los internacionalmente»(Roque, 2002, 133).

${ }^{12}$ Lobo Antunes, 1999.

${ }_{13}^{13}$ Moreira, 1997, 10.
} 
Da Arteriografia à Angiografia Cerebral e, depois, à Leucotomia Pré-frontal, EM constitui-se gestor de um dispositivo de produção técnico-científica, disputando a primazia dos seus produtos, publicando, fazendo-se representar quando impossibilitado de se deslocar ${ }^{14}$, multiplicando-se em contactos, convites, comunicaçôes e artigos.

Quando, em 14 de Março de 1939, EM sofreu o atentado em que foi baleado por um dos seus pacientes, o Daily Telegraph (entre outros) noticiou a ocorrência. Choveram, então, em Lisboa, mensagens de pesar e de inquietação pelo seu estado de saúde. Era óbvio tratar-se já de um cientista de renome. O mapa das suas viagens e pontos de influência posteriores a 1935, ano que marca o II Congresso Internacional de Neurologia de Londres, e o início das suas experiências ligadas à Leucotomia Pré-frontal, consistirá, em parte, de uma sobreposição da influência consolidada com a Arteriografia Cerebral, afectada pela emergência da II Grande Guerra, mas, por outro lado, alargada aos Estados Unidos da América, onde, por razōes desencontradas, Freeman e Wats, se tornam seus discípulos. Surgiu assim um novo e decisivo apoio na difusão da Psicocirurgia e no reconhecimento público da primazia de EM. Walter Freeman e James Wats modificaram o método de Moniz, que passaram a denominar Lobotomia Pré-Frontal, acrescentando-lhe a variante transorbital, igualmente derivada, em todo o caso, da Leucotomia Pré-frontal, método fundador da autoria de EM.

As suas viagens ulteriores, inscrevem-se na mesma senda. Dispensará, nas suas memórias, espaço e atenção diferenciados a cada uma delas - a viagem a Itália, em 1937, por exemplo, entre descrições de sessões de trabalho, cursos, experiências e fruição artística, ocupa mais de dois capítulos das Confidências de um Investigador Científico - mas a sensibilidade para a gestão do dispositivo que montou e de que a sua imagem permanece o ex-libris, permanece.

Sustentando implicitamente a existência de um dado equilíbrio entre a importância dos trabalhos de EM e esse savoir faire diplomático que aludimos, um outro neurocirurgião do nosso tempo estima que

«Para uma nova técnica diagnóstica ou uma terapêutica revolucionária serem adoptadas na prática médica corrente, é necessário que, em primeiro lugar, tragam solução a problemas até então por resolver. Mas é também indispensável que elas sejam apresentadas aos poderosos e influentes em cenários apropriados, além de publicadas nas revistas de maior prestígio. Egas Moniz foi um mestre na arte de comunicar ciência.» ${ }^{15}$

A nobelização de EM em 1949, constitui, pois, o corolário da obra de um homem atento aos nichos de oportunidade existentes na sua época, na sua profissão, e num espaço mais vasto do que o país onde nasceu. Em todo o caso, alguém «(...) extraordinariamente hábil na luta do mundo» ${ }^{16}$

\footnotetext{
${ }^{14}$ Saldanha, 1974, 7.

${ }^{15}$ Lobo Antunes, 1999, 6.

${ }^{16}$ Lobo Antunes, 1999, 7.
} 


\section{BIBLIOGRAFIA}

CASCAIS, António Fernando. (2001) «A cabeça entre as mãos: Egas Moniz, a psicocirurgia e o Prémio Nobel» in Nunes, João Arriscado e Gonçalves, Maria Eduarda. (Org.), Enteados de Galileu? A semiperiferia no sistema mundial da ciência, Porto, Afrontamento.

FERnANDES, Barahona. (1983) Egas Moniz, pioneiro de descobrimentos médicos, Lisboa, ICLP.

Lobo Antunes, J. (1999) "Prefácio» in Pereira, A. L., Pita, J. R., e Rodríguez, R. M., Retrato de Egas Moniz, Lisboa, Círculo de Leitores.

Moniz, Egas., (1949) Confidências de um Investigador Cientifico, Lisboa, Ática.

MOREIRA, Tiago (1997) Large gain for small trouble: the construction of cerebral angiography, Msc. In Science and Technology Studies, The University of Edinburgh.

Pereira, A. L., e PitA, J. R., org. (2000) Egas Moniz em livre exame, Coimbra, Minerva.

Roque, Maria Helena Neves, (2002) Positivismo e Visibilidade na Obra de Egas Moniz (1874-1955), Tese de Mestrado, Universidade Nova de Lisboa, Faculdade de Ciências e Tecnologia, Secção autónoma de Ciências Sociais Aplicadas.

Roque, Maria Helena Neves, (2000) «As Viagens científicas de Egas Moniz (1874-1955). Prémio Nobel de Medicina e Fisiologia 1949.» - Comunicação apresentada na 2a Conferência do STEP realizada em Lisboa na Fundação Calouste Gulbenkian. Disponível também no blog Digitalis, em [http://mhroque. blogspot.com/2003_02_16_mhroque_archive.html]

Saldanha, Aleu. (1974) "Egas Moniz - o cientista e o homem», in Separata de O Médico no 1212, Vol. LXXIII, pp. 423/425. 


\section{Colecçãa \\ 2 Ciências e Culturas Caimbra 2006}

